\title{
Optimization of Extended Surfaces on Tubes of The Radiant Section of Fired Heaters
}

\author{
Ivan C. Silva ${ }^{1}$ and Marcelo J. Colaço ${ }^{2}$ \\ ${ }^{1}$ PETROBRAS - Petróleo Brasileiro S.A. Research Center (CENPES) \\ Av. Horácio Macedo, 950, 21941-915 Rio de Janeiro, Brazil \\ Email: ivan.costa@petrobras.com.br \\ ${ }^{2}$ Department of Mechanical Engineering \\ Federal University of Rio de Janeiro (PEM-COPPE/UFRJ) \\ Cx. Postal 68503, 21941-972, Rio de Janeiro, Brazil \\ Email: colaco@ufrj.br
}

\begin{abstract}
This paper proposes the use of non-uniform extended surfaces installed externally to the tubes of the radiation section of fired heaters, in order to obtain a better heat flux distribution to the coils. To this end, the heat transfer mechanisms present in such equipment were studied through computational fluid dynamics (CFD), using simplified geometries that represent typical sizes of fired heaters. Also, a simplified model for the combustion was considered. Although this model oversimplifies the physics of the problem, it was able to give satisfactory results for the parameters being optimized, considering the main objective of this paper, that is to minimize the non-uniformity of heat flux in the tubes of the radiant section of fired heaters. It was possible to obtain optimized geometric parameters for different types of extended surfaces evaluated, coupling the results of these models with the Particle Swarm optimization method using a response surface technique. The results indicate a significant improvement in the uniformity of the heat flux distribution to the tubes through the use of the proposed extended surfaces. Thus, this solution reveals to be an interesting alternative to reduce the risks of fluid degradation and coking formation. Future studies must investigate the non-uniformity of the heat flux due to the presence of the flame and consider the interaction between the reactive flow and the participating medium. Nevertheless, this paper presents some results that justify the optimization of such extended surfaces taking into consideration thermal radiation.
\end{abstract}

Keywords: optimization; particle swarm; response surface; extended surface; fired heaters; computational fluid dynamics

\section{INTRODUCTION}

Fired heaters are combustion equipment present in many process plants where there is a need to provide thermal energy to a fluid in order to heat it, vaporize it or promote chemical reactions. In refineries they are major energy consumers, directly impacting the operation costs and profitability.

In these equipment part of the energy released by the combustion is transferred to the fluid circulating inside the tubes placed in the combustion chamber. Radiation is the main heat transfer mechanism, due to 
Optimization of extended surfaces on tubes of the radiant section of fired heaters

the high temperatures achieved and the participation of asymmetric diatomic gases generated in the combustion, mainly $\mathrm{CO}_{2}$ and $\mathrm{H}_{2} \mathrm{O}$.

In most fired heaters the tubes are placed against the combustion chamber walls, while the burners are positioned at the central region, according to the example illustrated in Figure 1. This configuration, called single fired, leads to an irregular circumferential heat flux distribution to the tubes, since the side facing the flame receives a greater amount of radiated thermal energy than the side facing the refractory, resulting in higher local heat flux and tube wall temperature.

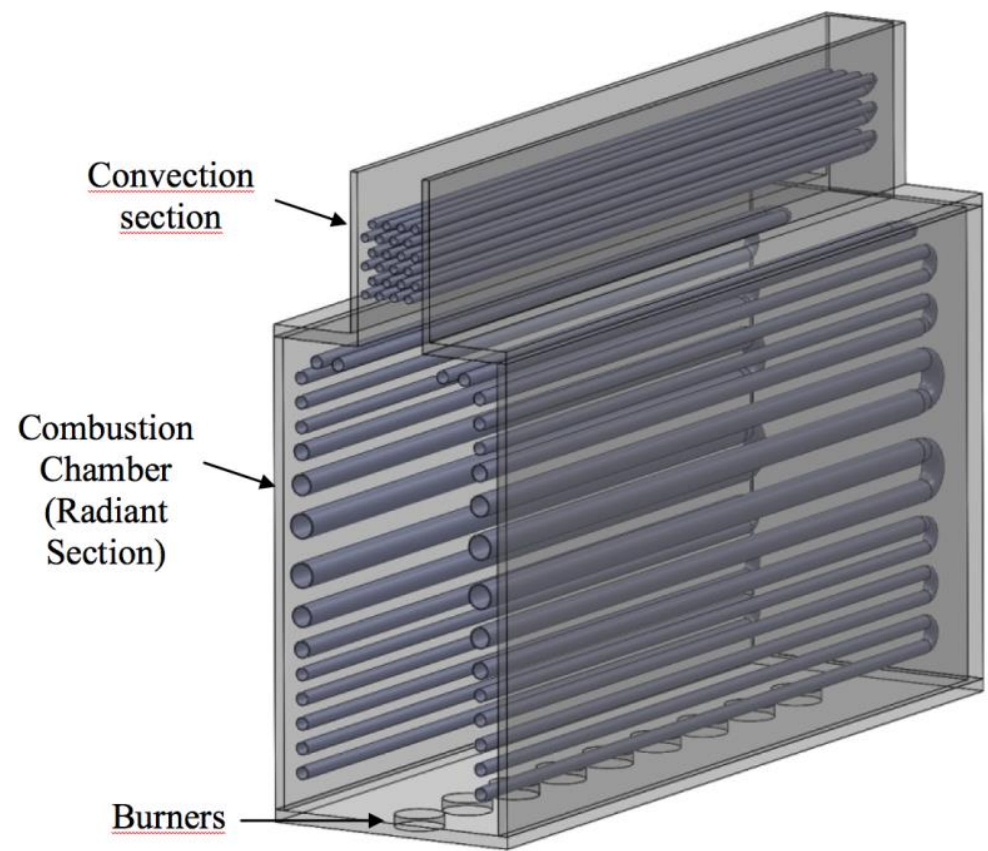

Figure 1. Schematic representation of a fired heater.

Another cause of variation in the distribution of the heat flux to the tubes is their position inside the combustion chamber. Tubes closer to the burners or subjected to a higher convection with the hot flue gas have higher heat flux.

The presence of high heat flux areas in fired heater coils lead to several operational problems, such as process fluid degradation and formation of coke deposits on the inner surface of the tubes [1-3]. By having insulating characteristics, in severe cases these deposits can reduce the fired heater capacity or lead to tube failure due to high temperature, requiring a costly tube decoking process.

Some alternatives to improve the heat flux distribution at the coils might include the use of a double fired arrangement [4], where the tubes are positioned in the middle region of the combustion chamber with burners on both sides, and the use of larger distances between the tubes. However, these configurations result in increased manufacturing costs. The use of steam injection points and reduced tube diameters, in order to increase the internal heat transfer coefficient, are options also found in the literature [5], but they may cause operational difficulties, such as a high pressure drop.

Due to the complex heat transfer mechanisms present inside a combustion chamber, ruled by the processes of combustion and gas flow, numerical studies using computational fluid dynamics (CFD) becomes essential to model the behavior of these equipment in order to understand and predict the effects 
of changes in the operating variables. Given the importance of combustion in industry processes, several studies have been conducted in order to create numerical models capable of describing this phenomenon $[6,7]$. Radiation, the main heat transfer mechanism associated with combustion, has also been the subject of interest and numerous models have been proposed in order to predict its behavior, especially in the presence of participating medium [8]. Using these advances in models describing the heat transfer and fluid flow mechanisms present in combustion systems, many studies have been conducted to evaluate the performance of real fired heaters using CFD software [9-11]. These evaluations successfully allowed observing the influence of operating variables on the heat transfer to the coils and the effects of non-uniform heat flux distribution described above. However, the search for solutions to improve the heat flux distribution to the fired heaters tubes was not the main focus of these studies.

Since the circumferential heat flux variation is the major effect that increases the ratio between the maximum and the mean heat flux to the tube coils in single fired heaters [12], a more uniform heat flux would lead to lower risk of fluid degradation and coke formation, allowing the design of combustion chambers with higher heat transfer capacity and longer operation times.

Thus, this study proposes the use of non-uniform extended surfaces installed externally to the tubes of the radiation section of fired heaters, in order to obtain a better heat flux distribution to the coils. For this purpose, simplified finite volume numerical models were used to represent the heat transfer mechanisms present in this equipment. In order to obtain the best geometric parameters for two different extended surfaces profiles (trapezoidal and parabolic), the Particle Swarm optimization method was used together with a Response Surface technique.

\section{PHYSICAL PROBLEM}

\subsection{Extended surfaces}

The extended surfaces proposed in this study are circular type fins with two different profiles: trapezoidal and parabolic, as illustrated in Figure 2. The thickness of the tip $\left(2 w_{p}\right)$ and the fin height were kept fixed, equal to $1.27 \mathrm{~mm}$ and $25.4 \mathrm{~mm}$ respectively, as recommended limits [13] for the convection section tubes. A distance between the bases of the fins was also used with a constant value of $5 \mathrm{~mm}$, in order to provide a suitable space for fixing the fins to the tubes. Thus, an increase in the thickness of the fin base $\left(2 w_{b}\right)$ leads to a reduction in the number of fins per tube unit length.

In order to avoid increasing the maximum heat flux in the tubes, the proposed fins do not extend throughout the circumference of the tubes. In this way, the tube side facing the flame was maintained with a bare surface, and the fin extension was defined by the variable $\omega$ shown in Figure 3. 
Optimization of extended surfaces on tubes of the radiant section of fired heaters
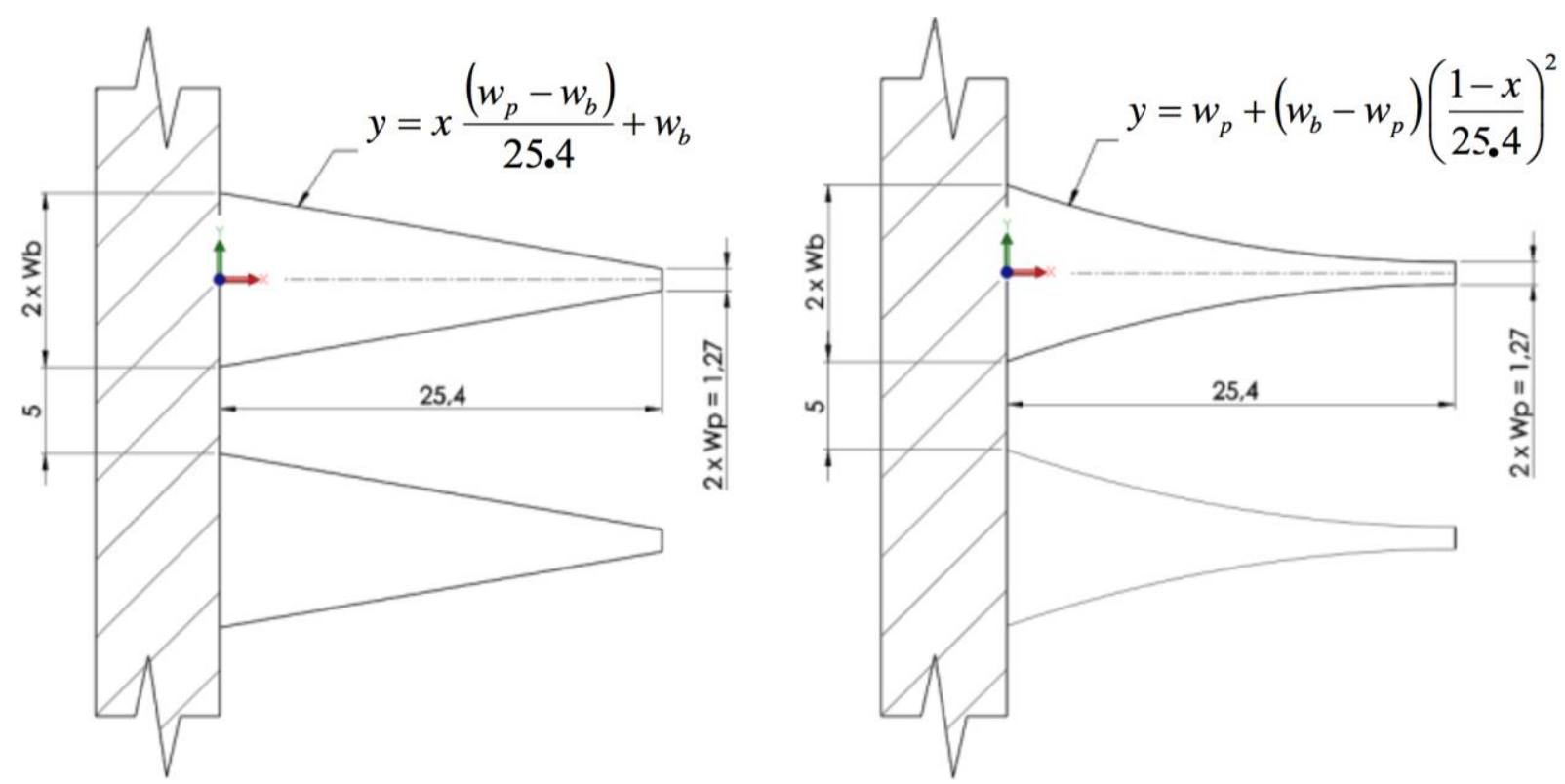

Figure 2. Trapezoidal and parabolic fins (dimensions in $\mathrm{mm}$ ).

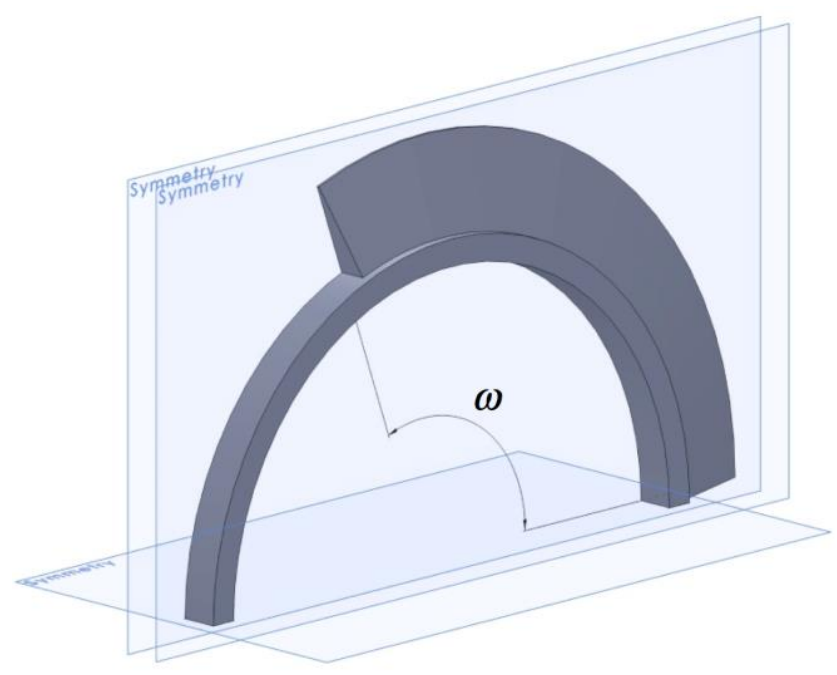

Figure 3. Fin extension angle.

\subsection{Simplified model - radiation only}

Since radiation is the main heat transfer process to the coils in fired heaters combustion chambers, this first model considers only this mechanism. The geometry analyzed is illustrated in Figure 4, where a hot surface, representing the flame, irradiates heat to a tube bank against a wall. 


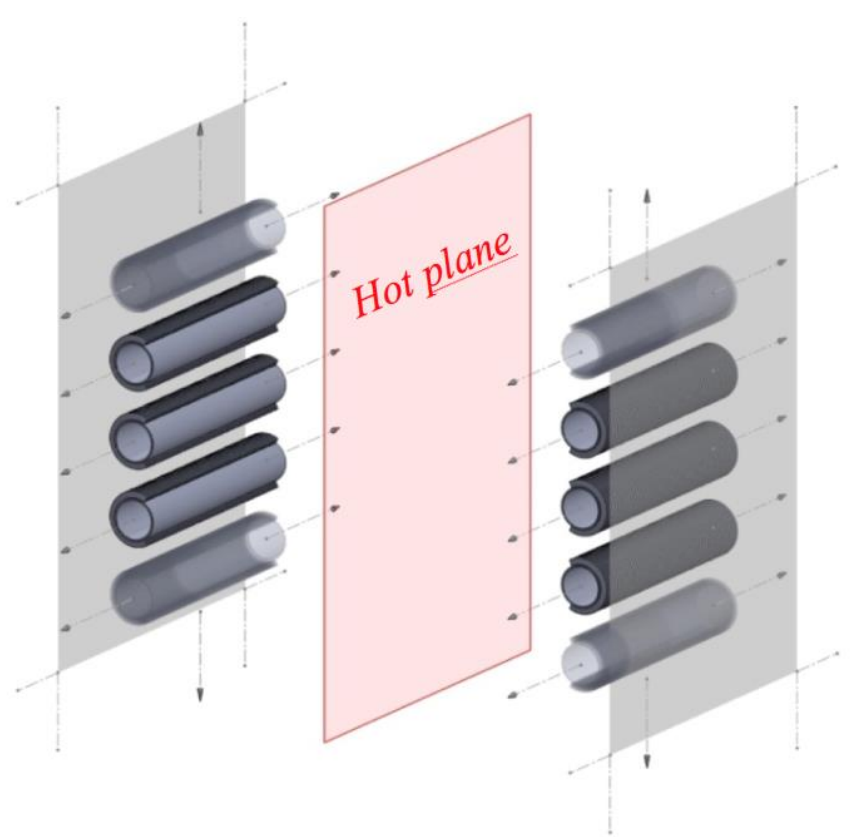

Figure 4. Geometry used in the simplified model.

Although the use of a hot plane oversimplifies the combustion process, it was able to give satisfactory results for the parameters being optimized, as it will be discussed next. This approach was used since most fired heater designers evaluate the heat transfer to the tubes inside the combustion chamber based on the model developed by Lobo and Evans [14]. In this simplified calculation, called well stirred, the temperature of the flue gases is considered uniform and pipe coils are approximated by heat exchange plane surfaces. The result of this evaluation is an average heat flux to the tubes inside the combustion chamber. In order to determine the maximum heat flux to which the tubes are subjected, the API STD 530 [12] provides a method for estimating this value through correction factors applied on the average heat flux. The main factors refer to the influences described above, regarding the circumferential distribution $\left(F_{c i r}\right)$ and positioning of the tube within the combustion chamber $\left(F_{L}\right)$. The $F_{c i r}$ factor, shown in Eq. (1), is defined as the ratio between the maximum $\left(q_{\max }\right)$ and average $(\bar{q})$ heat flux on the perimeter of the tubes. The values proposed by the API STD 530 for the $F_{\text {cir }}$ factor are based on the heat transfer by radiation between a hot plane and tube rows, as represented by the simplified model used in this work.

$$
F_{c i r}=\frac{q_{\max }}{\bar{q}}
$$

Using appropriate symmetry boundary conditions, the model may be reduced to the geometry represented in Figure 5. In this model, only the circumferential heat flux variation effect is present, since all the tubes have the same boundary conditions. 


\section{Optimization of extended surfaces on tubes of the radiant section of fired heaters}

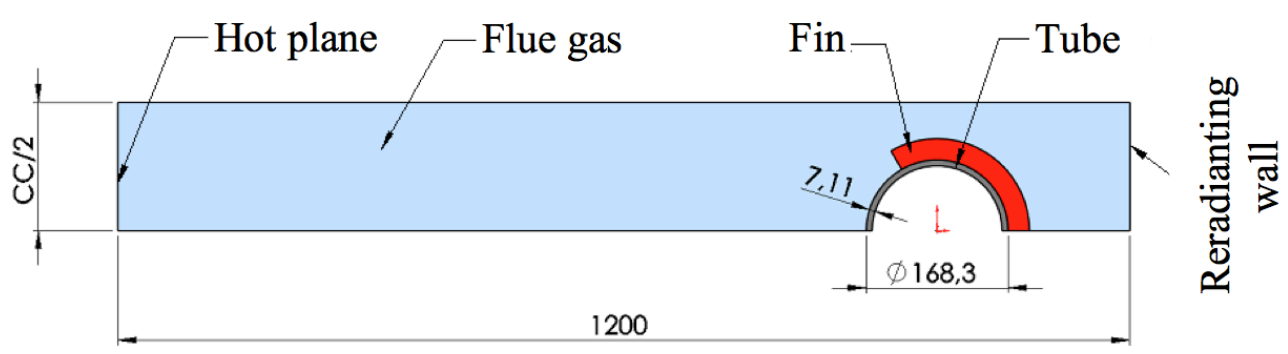

Figure 5. Frontal view of the simplified model domain (dimensions in $\mathrm{mm}$ ).

The dimensions used represent typical values found in fired heaters. The distance between the hot plane and the tubes is adequate for $2 \mathrm{MW}$ burners [13]. Tube dimensions were chosen as 6" schedule 40, present in many refineries heaters. The thermal conductivity considered for the tube and extended surface was typical for a $9 \% \mathrm{Cr}-1 \%$ Mo steel.

The boundary conditions used were zero heat flux at the reradiating wall, convective heat transfer at the inside tube face and prescribed temperature at the hot plane. The convection parameters considered for the inside tube surface were typical for a thermal oil heater [15]: $300{ }^{\circ} \mathrm{C}$ bulk temperature and $1000 \mathrm{~W} \cdot \mathrm{m}^{-2} \cdot \mathrm{K}^{-1}$ of heat transfer coefficient. Circumferential variations on the internal heat transfer coefficient were neglected, since the effects external to the tubes are much more relevant. However, in future studies, these effects may be taken into consideration, especially if one intends to analyze the coke formation and/or fluid degradation inside these tubes. The hot plane temperature was adjusted for a heat flux of $37,855 \mathrm{~W} \cdot \mathrm{m}^{-2}$ on the external surface of the tubes, a usual value adopted in different fired heater services [15]. The tube emissivity was considered as 0.9 and the reradiating wall emissivity was considered as 0.7 , based on typical values for ceramic materials [16]. All surfaces were considered opaque and diffuse.

The medium was considered as a stationary flue gas with known composition, based on the products of the methane combustion with $15 \%$ excess air, recommended value for gas fired natural-draught process burners [13], given by Eq. (2). The temperature was considered fixed and equal to $750^{\circ} \mathrm{C}$.

$$
1 \mathrm{CH}_{4}+1.15\left(2 \mathrm{O}_{2}+7.52 \mathrm{~N}_{2}\right) \rightarrow 1 \mathrm{CO}_{2}+2 \mathrm{H}_{2} \mathrm{O}+0.3 \mathrm{O}_{2}+8.65 \mathrm{~N}_{2}
$$

In order to verify the previous approach, we considered a distance between the centerline of the tubes and the heater wall equal to 1.5 times the nominal diameter of the tubes. This is the standard distance used by the majority of the manufacturers and also the minimum value recommended by the API STD 560 standard. Figure 6 shows a comparison between the current results and the ones presented in the API STD 560 standard, both for single and double fired heaters for the $F_{\text {cir }}$ factor. 
Optimization of extended surfaces on tubes of the radiant section of fired heaters

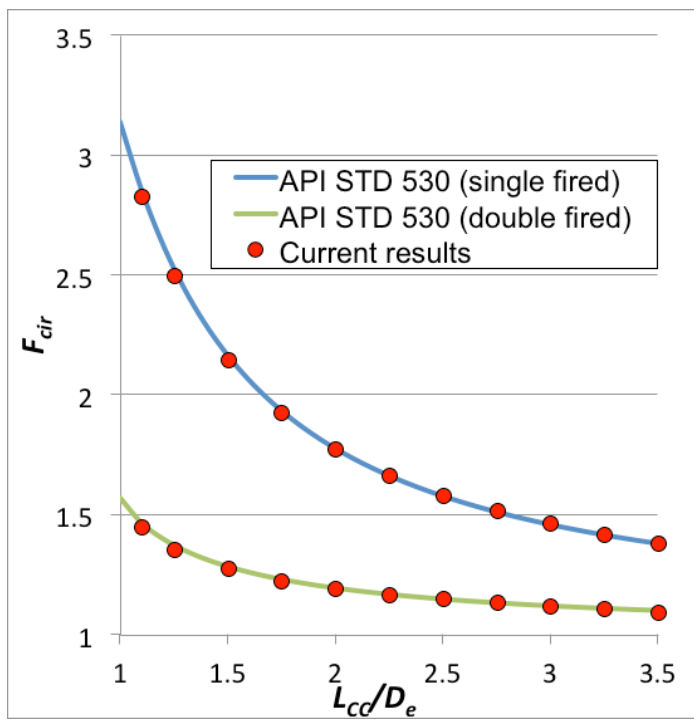

Figure 6. Comparison between current results the API STD 560 for the $F_{\text {cir }}$ factor.

In Fig. $6, D_{\mathrm{e}}$ is the external diameter of the tubes and $L_{\mathrm{cc}}$ is the distance between the centerline of two tubes. Results for the $F_{c i r}$ factor agree very well with the ones reported by the API Standard, which shows that the proposed geometry, the radiation model and the mesh used are suited to evaluate the effects of irregular circumferential distribution of radiation to fired heater tubes. Since the objective of this paper is to optimize such factor, as it will be discussed next, and not analyze the fluid flow process in details, the authors believe that the employed approximations are valid for this initial study. Nevertheless, future works shall take into consideration the interaction of the burners and the influence of the inhomogeneous heat flux along the flame.

\subsection{Refined model - radiation and convection}

In order to include the effects of convection, as well as to add different boundary conditions for the tubes, representing the positioning effects within the combustion chamber, a more elaborate model is proposed. The geometry, shown in Figure 7, represents an infinite length box type combustion chamber with ten horizontal tubes placed against the side walls.

As in the simplified model, the combustion was not modeled and the flame was approximated by a hot plane, where the height respected the limit of $2 / 3$ of the combustion chamber [13]. In this plane a free surface boundary condition was adopted, avoiding wall effects on the flow. The boundary conditions used for the other surfaces were the same considered in the simplified model. For the inlet condition a fixed gas composition was considered according to Eq. (2). A porous medium was included at the flue gas exit in order to simulate the pressure drop caused by the convection section tube banks.

Analyzing the energy balance in the proposed problem, the heat released in the system $\left(q_{r e l}\right)$ is given by the sum of the net heat transfer in the hot plane and the sensible heat of the inlet flue gas. By changing the temperature and the flow rate of the inlet flue gas and the temperature and emissivity of the hot plane, the boundary conditions for the tubes are changed, affecting the resulting heat flux for a given total heat released. 


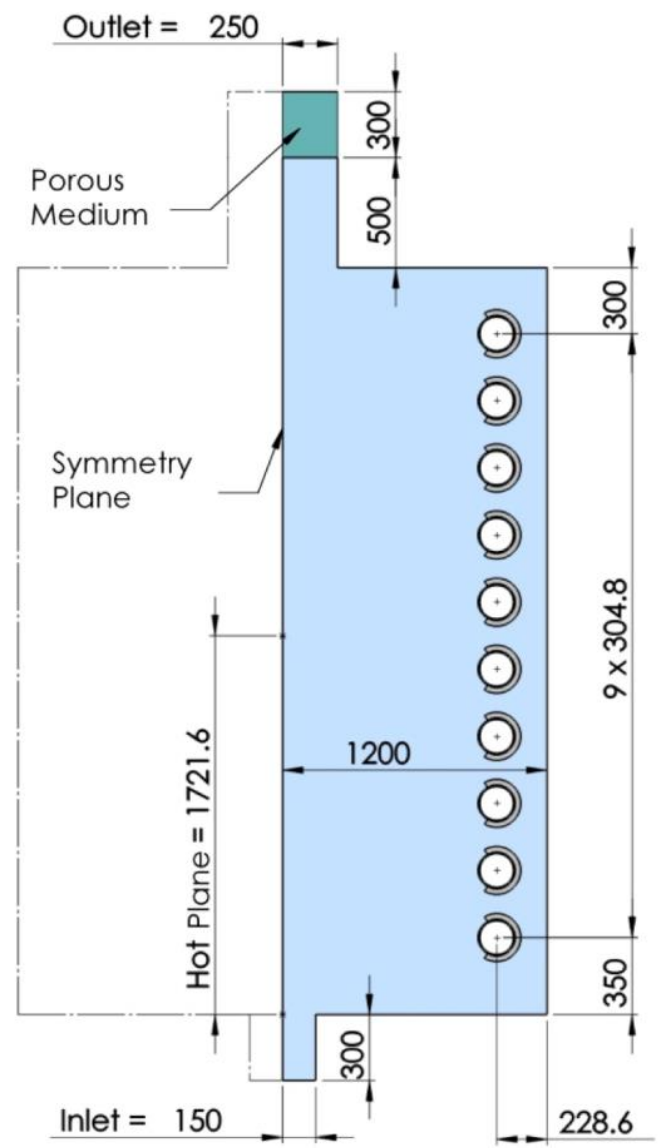

Figure 7. Frontal view of the refined model domain (dimensions in $\mathrm{mm}$ ).

In order to determine the total heat release per unit length of the combustion chamber required for an average heat flux on the outer surface of the tubes of $37,855 \mathrm{~W} \cdot \mathrm{m}^{-2}$, the software PFR FRNC5-PC was used. This software uses the well stirred methodology [14] to determine the average heat transfer in fired heaters, based on the geometry of the combustion chamber, flue gas $\mathrm{CO}_{2}$ and $\mathrm{H}_{2} \mathrm{O}$ partial pressures and tube temperature. Since obtaining experimental data in real fired heaters is quite difficult, given the large dimensions and extreme operating conditions of these equipment, the use of the PFR FRNC-5PC software was chosen to calibrate the model in this paper. This software has been used by several designers and fired heater users in order to simulate the performance of these equipment. It was also a computational tool adopted in many theoretical works, as Lowe et al. [17], Jiao et al. [5] and Morales-Fuentes et al. [18].

Using this result, the inlet flue gas mass flow rate $\left(m_{f g}\right)$ can be determined based on the lower heating value of the fuel (LHV) and the mass relation between the flue gas and the fuel $\left(R_{f g, f}\right)$ :

$$
\begin{gathered}
m_{f g}=R_{f g, f} \frac{q_{r e l}}{L H V} \\
R_{g c, c}=\frac{1 M W_{\mathrm{CO}_{2}}+2 M W_{\mathrm{H}_{2} \mathrm{O}}+0.3 M W_{\mathrm{O}_{2}}+8.648 M W_{N_{2}}}{1 M W_{\mathrm{CH}_{4}}}=20.734
\end{gathered}
$$


The next step was to adjust the hot plane emissivity and temperature, which led to the same result of average heat flux to the tubes $\left(37,855 \mathrm{~W} \cdot \mathrm{m}^{-2}\right)$ for the heat release determined by the PFR FRNC5-PC.

It is considered that the model adopted, despite the simplifications, fully meet the desired goal, which is to provide an environment similar to that found in combustion chambers in order to obtain boundary conditions alike those found in fired heater tubes.

\section{FLUID FLOW AND HEAT TRANSFER MODELS}

The ANSYS FLUENT software was used to solve the problems described above through the finite volumes method. The models used to describe the fluid flow and heat transfer mechanisms are briefly commented below.

\subsection{Fluid flow}

All simulations were performed for the steady state case. In order to include the effects of turbulence, the realizable $\mathrm{k}-\varepsilon$ model [19] was used. This model is more adequate to represent recirculating and expansion regions, in comparison with the standard $\mathrm{k}-\varepsilon$. The realizable model uses a different formulation for both the turbulent viscosity and the transport equation for the dissipation rate $(\varepsilon)$.

For the wall effects on the fluid flow, the Enhanced Wall Treatment (EWT) [20], was used. This model combines a two-layer approach with scalable wall functions, reducing the mesh refinement influence on the results. The two-layer formulation divides the domain, defining a region affected by the presence of the walls, where the realizable k- $\varepsilon$ formulation is modified. For the control volumes adjacent to the walls, a linear and a logarithm wall function models are combined to define the fluid flow, based on the $\mathrm{y}+$ parameter

In the porous region a source term was included in the momentum conservation equation to simulate losses due to inertial effects. The parameters were adjusted for a pressure drop of $50 \mathrm{~Pa}$.

\subsection{Heat transfer}

The turbulent influence in the convection heat transfer was included in the enhanced wall treatment model (EWT), as well as buoyancy effects caused by the flue gas temperature variation.

The radiation properties were obtained by the weighted sum of gray gases (WSGG) [21]. This model simulates the spectral dependence of gases absorption coefficients based on the partial pressure of the $\mathrm{CO}_{2}$ and $\mathrm{H}_{2} \mathrm{O}$, and the flue gas temperature.

The radiation heat transfer was evaluated by the Discrete Ordinates (DO) [22] method. This model divides the domain into a discrete number of directions $(\vec{s})$, each one associated to a weight factor, where the radiation intensity $(I)$ transport equation has to be solved. For this study the refractive and scattering effects were neglected, and the radiation equation was reduced to:

$$
\frac{d I(\vec{r}, \vec{s})}{d s}=k_{T} \frac{\sigma T^{4}}{\pi}-k_{T} I(\vec{r}, \vec{s})
$$

where the first term on the right-hand side represents the radiation intensity gain due to the gas emissions and the second term account for the gas absorption. 
Optimization of extended surfaces on tubes of the radiant section of fired heaters

The meshes were generated using only hexahedral elements through the sweep method, available in the ANSYS Meshing software. This type of mesh allows a smaller number of control volumes for the discretization of the domain in comparison with tetrahedral elements, reducing the computational costs. Furthermore, the use of hexahedral elements enabled that large part of the mesh faces were aligned with the Cartesian coordinate system, reducing numerical errors of the DO model. Proper refinement was used in order to eliminate mesh influence on the results, especially close to the tubes as shown in Figure 7. A total number of 17,328 integration cells were used in the simplified model and 381,876 integration cells were used in the refined model. A second verification of the grid convergence analysis of the final results will be presented in the next sections.

\section{OPTIMIZATION MODEL}

The objective function used in this study was the minimization of the $F_{\text {cir }}$ factor, shown in Eq. (1), obtained by solving the simplified model.

The optimization variables adopted were the fin base thickness $\left(w_{b}\right)$ and the extension angle $(\omega)$. Thus, to obtain a better circumferential heat flux distribution, the $F_{c i r}$ ratio must be minimized.

Since the numerical solution of the finite volume models requires considerable computation time, a response surface technique was used in order to replace the finite volume model solution in each optimization iterative step by a fast response approximate model [23].

To this end, the finite volume model was initially solved for a number of discrete points $\left(P_{j}\right)$ formed by combinations of the variables $\left(\omega, w_{b}\right)_{j}$ in order to create a representative initial population of the evaluated domain.

From these results, the adopted response surface $\left(f_{r s}\right)$ was obtained by a multiquadric radial basis function (RBF) with a second order polynomial term, given by [23]:

$$
\begin{gathered}
f_{s r}\left(P_{i}\right) \cong \sum_{j=1}^{N_{\text {pop }}} \alpha_{j} \varphi\left(\left\|P_{i}-P_{j}\right\|\right)+\sum_{k=1}^{2} \sum_{l=1}^{2} \beta_{l, k} p_{i, l}^{k}+\beta_{0} \\
\varphi\left(\left\|P_{i}-P_{j}\right\|\right)=\sqrt{\left\|P_{i}-P_{j}\right\|^{2}+c^{2}}
\end{gathered}
$$

To obtain the $\alpha_{j}, \beta_{l, k}$ and $\beta_{0}$ parameters, the following restrictions were imposed [23]:

$$
\begin{gathered}
\sum_{j=1}^{N_{p o p}} \alpha_{j} \sqrt{\left\|P_{i}-P_{j}\right\|^{2}+} c^{2}+\sum_{k=1}^{2} \sum_{l=1}^{2} \beta_{l, k} p_{i, l}^{k}+\beta_{0}=F_{c i r}\left(P_{i}\right) \\
\sum_{j=1}^{N_{p o p}} \alpha_{j} p_{j, i}^{k}=0 \\
\sum_{j=1}^{N_{p o p}} \alpha_{j}=0
\end{gathered}
$$


Optimization of extended surfaces on tubes of the radiant section of fired heaters

The pair of variables $\left(\omega, w_{b}\right)$ which minimizes the response surface was obtained by the Particle Swarm optimization method $[23,24]$. The procedure is based on the social behavior of different species in nature, using effects of individuality and sociability in order to determine an optimal search direction. The algorithm is given by:

$$
P_{i}^{k+1}=P_{i}^{k}+\beta_{1} r_{1, i}\left(\pi_{i}-P_{i}^{k}\right)+\beta_{2} r_{2, i}\left(\pi_{g}-P_{i}^{k}\right)
$$

where $k$ is the iteration step index, $r_{1}$ and $r_{2}$ are uniform random numbers varying from 0 to 1 , and the constants $\beta_{1}$ and $\beta_{2}$, taken as 2 in this study, define the search range. The best position obtained by the $\mathrm{i}^{\text {th }}$ individual $\left(\pi_{1}\right)$ is the responsible for the individuality, and the best position obtained by all the individuals $\left(\pi_{\mathrm{g}}\right)$ is the responsible for the sociability.

\section{RESULTS}

\subsection{Extended surface optimization}

First, the influence of the optimization variables on the heat flux distribution to the tubes was evaluated. To this end, some cases were simulated using the trapezoidal fins. Figure 8 a shows that the $F_{\text {cir }}$ factor rapidly increases for large values of $\omega$. This change in behavior is explained by the displacement of the maximum heat flux point, which goes from the tube side facing the hot plane to the fin base region, close to the maximum value of $\omega$. In all cases, $w_{\mathrm{p}}$ was set to $0.635 \mathrm{~mm}$ as discussed before. Figure $8 \mathrm{~b}$ shows that trapezoidal profiles $\left(w_{b}>w_{p}\right)$ generally perform better than rectangular profiles $\left(w_{b}=w_{p}\right)$, justifying their use in this application. It is also noted that within the evaluated range of variables the behavior of the objective function is less sensitive to the fin base thickness compared to the effects of the fin extension angle.
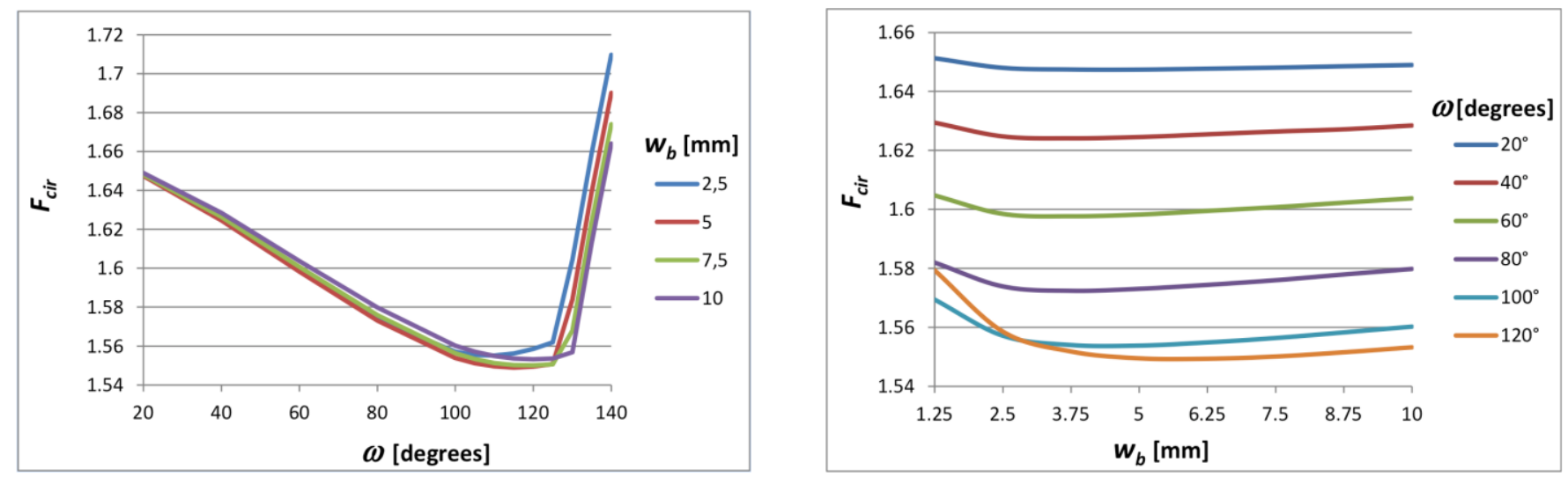

(a)

Figure 8. Variables influence in the heat flux distribution.

From these results, a searching domain was adopted with $\omega$ ranging from $105^{\circ}$ to $125^{\circ}$ and $w_{b}$ between 2.5 and $10 \mathrm{~mm}$. For the initial population, combinations of $\omega$ varying in increments of $5^{\circ}$ and $w_{b}$ varying in 


\section{Optimization of extended surfaces on tubes of the radiant section of fired heaters}

increments of $1.25 \mathrm{~mm}$ were used, resulting in a total of 35 points to be evaluated by the finite volumes model for each type of extended surface.

The obtained response surfaces are shown in Figure 9. The main difference between the two types of extended surface was the effect of the variable $w_{b}$ on the heat flux distribution to the tubes, since the parabolic profile gradients were more pronounced for small values of the fin base thickness. It is possible to see that both response surfaces had a unimodal behavior in the evaluated domain, which would allow the use of deterministic optimization models [23], based on the gradient of the objective function. However, as the behavior of the objective function was not known at the beginning, the Particle Swarm model was adopted since it has a good performance both for unimodal and multimodal functions, as confirmed from examples obtained from literature [23]. Also, the comparison of different optimization models was not the objective of this study.

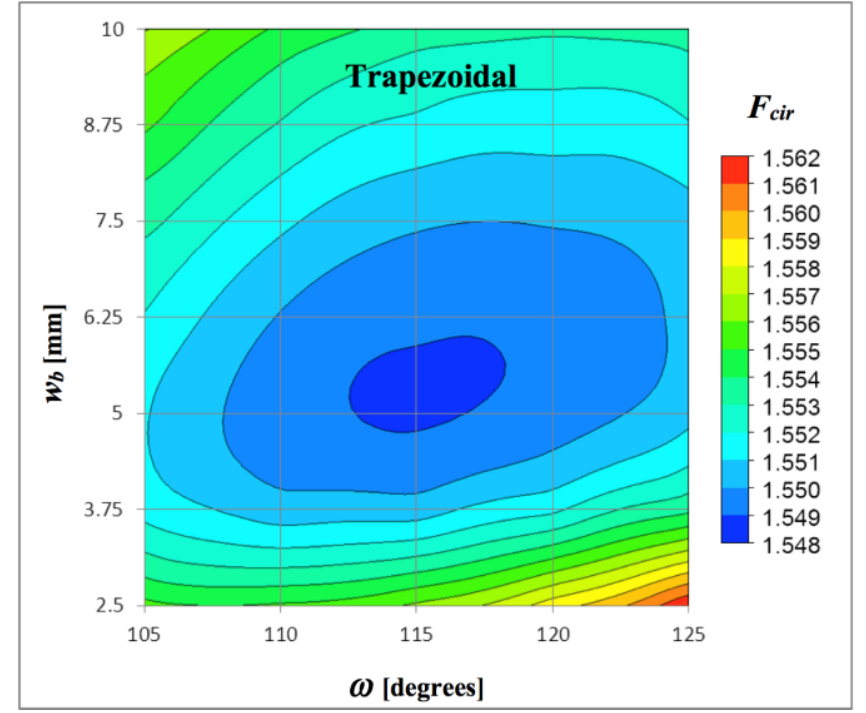

(a)

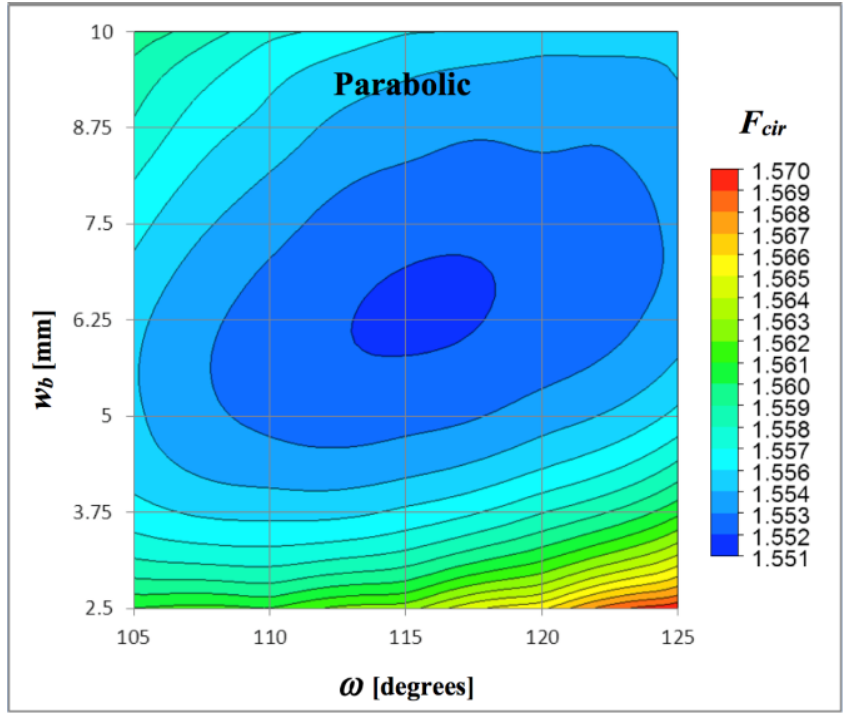

(b)

Figure 9. Response surfaces for the trapezoidal and parabolic fin profiles.

Using the Particle Swarm optimization method it was possible to obtain the following optimum parameters for the two types of fins studied: $w_{b}=5.2 \mathrm{~mm}$ and $\omega=114.1^{\circ}$ for the trapezoidal profile, and $w_{b}=6.3 \mathrm{~mm}$ and $\omega=115.0^{\circ}$ for the parabolic profile. These two configurations were evaluated in the physical model and the relative errors obtained, compared to the results predicted by the response surfaces, were $3.3 \times 10^{-5}$ and $7.6 \times 10^{-5}$ for the trapezoidal and parabolic profiles respectively, indicating a good accuracy of the RBF model based on the selected initial populations.

A comparison between the heat flux distribution obtained with the trapezoidal fin and the bare tube is illustrated in Figure 10 (the results obtained for the parabolic fin were very similar). It's possible to see that the fin promotes an increase in heat flux, especially in the region close to the maximum $\omega$ angle. Also, the value of the maximum heat flux (represented by the discontinuous red line) is not exceeded, which would increase the $F_{c i r}$ factor, as shown in Figure 8a for high $\omega$ values. 
Optimization of extended surfaces on tubes of the radiant section of fired heaters

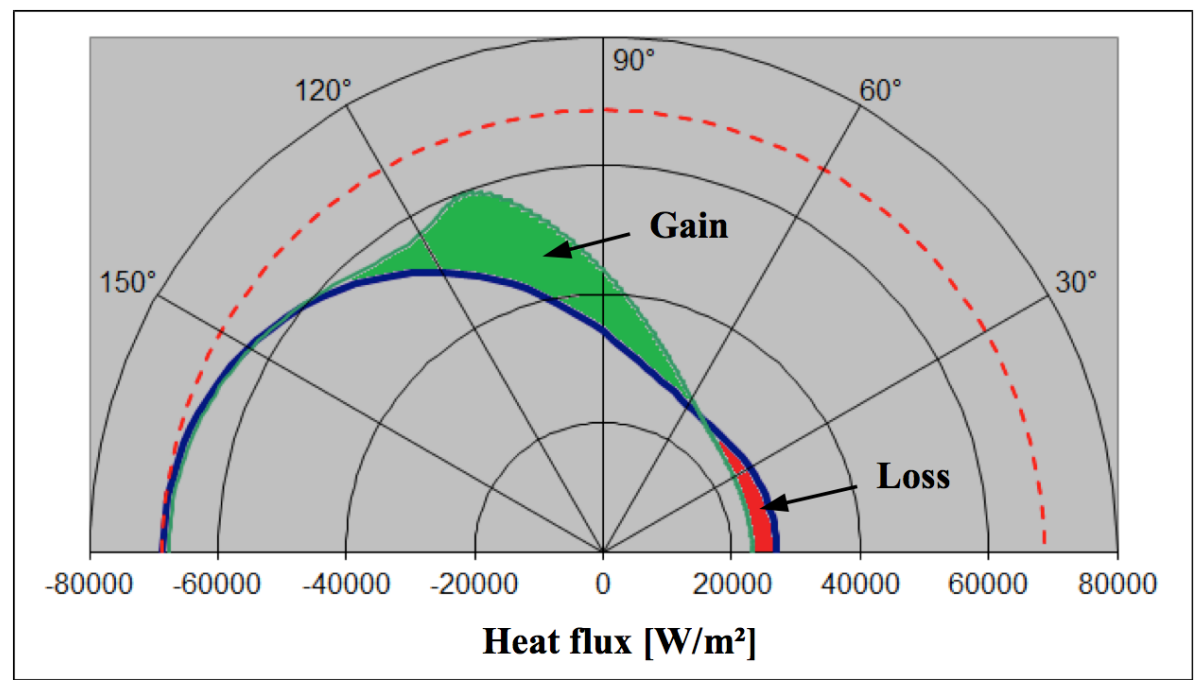

Figure 10. Heat flux distribution along the inner surface of the bare tube and with the optimized trapezoidal fin.

These results led to a reduction of the difference between the maximum and mean heat flux of $17 \%$ with the trapezoidal profile and $16 \%$ with the parabolic profile. However, the parabolic fin obtained with the optimization method resulted in a total volume $24.8 \%$ lower than that obtained with the trapezoidal profile, which could allow the production of a more economical and light equipment.

An analysis of the temperature profile, presented in Figure 11, revealed that for the considered conditions the maximum temperature obtained for the fins was less than $475{ }^{\circ} \mathrm{C}$. Therefore, for the considered conditions the fins did not reach the temperature limits recommended for low Cr steels [13]. However, in more severe applications the use of stainless steel may be required.

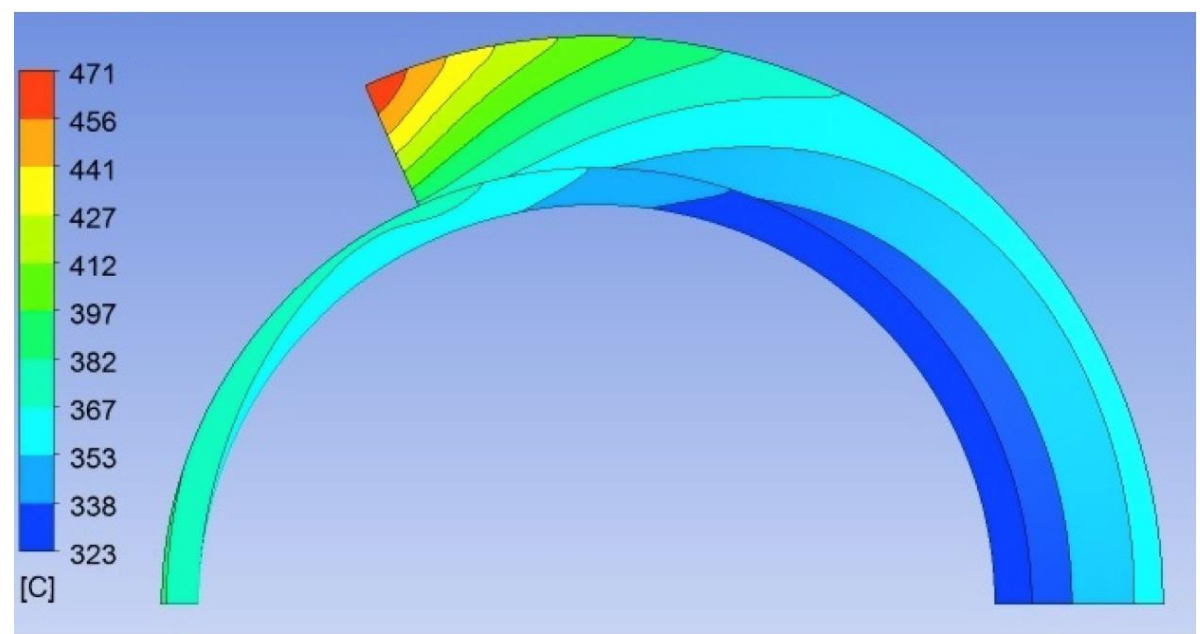

Figure 11. Temperature distribution with the optimized trapezoidal fin.

\subsection{Evaluation in the refined model}

The software PFR FRNC-5PC has determined a heat release per unit length of the radiation chamber proposed in the refined model of $709 \mathrm{~kW} \cdot \mathrm{m}^{-1}$ to obtain an average heat flux of $37,855 \mathrm{~W} . \mathrm{m}^{-2}$ on the tubes. 
Optimization of extended surfaces on tubes of the radiant section of fired heaters

From this result, the emissivity and temperature of the hot plane were adjusted to 0.15 and $1388{ }^{\circ} \mathrm{C}$ in order to provide the same results in the refined finite volume model.

The ratio between the higher average heat flux among the 10 tubes $\left(\bar{q}_{\max }\right)$ and the total average heat flux $(\bar{q})$ was 1.23, which is consistent with the 1.0-1.5 range recommended for the $F_{L}$ factor [12] defined in Eq. (12).

$$
F_{L}=\frac{\bar{q}_{\max }}{\bar{q}}
$$

Convection was responsible for $11.4 \%$ of the heat transfer to the tubes, a result close to the typical value of $15 \%$ found in the literature [9]. Thus, the proposed refined model attends the purpose of providing boundary conditions for the tubes close to those found in fired heaters.

The fins obtained by the optimization method applied to the simplified model were introduced into the refined model in order to evaluate the impact of including the effects of convective heat transfer and the position of the tubes within the combustion chamber.

Results presented in Figure 12 show that the two types of evaluated fins obtained performances very close to each other, providing a significant decrease of the $F_{\text {cir }}$ factor for tubes 1 to 8 , where tube 1 is the closest one to the combustion chamber floor. However, for tubes 9 and 10 the heat flux distribution was not very good.

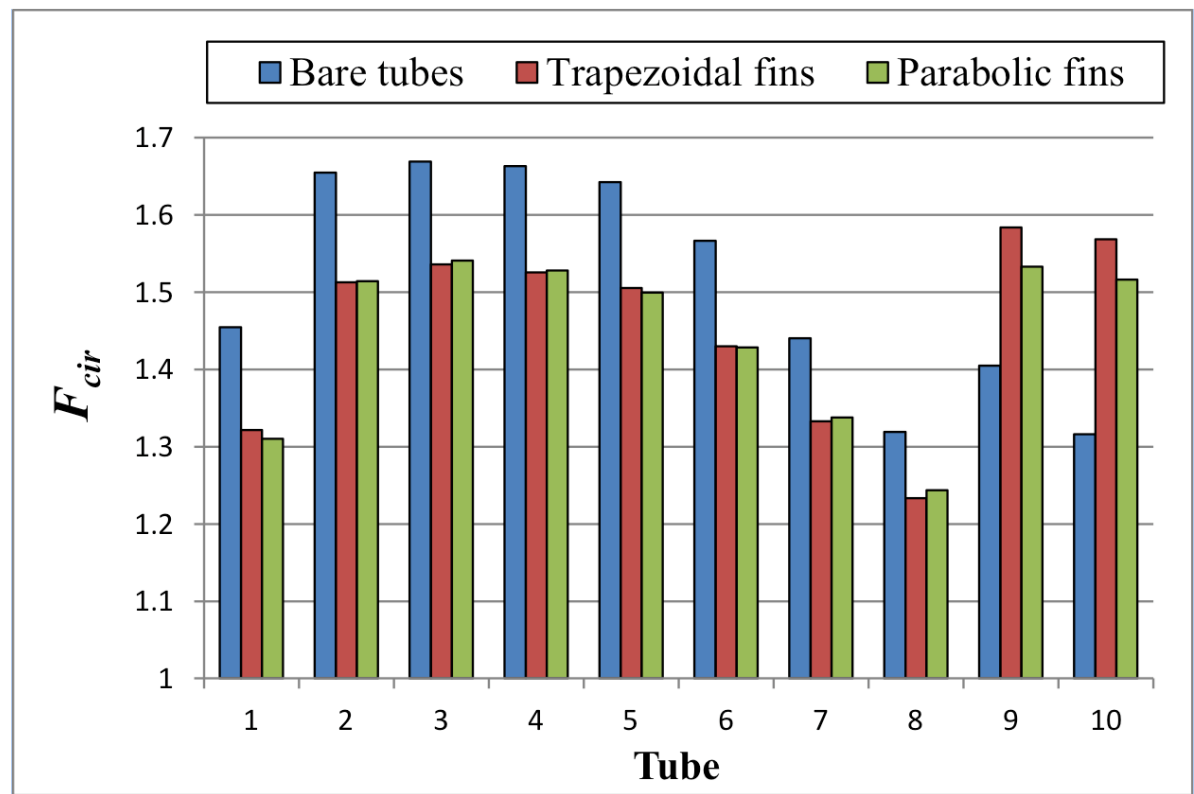

Figure 12. Comparison of the circumferential heat flux distribution to the tubes.

Figure 13 shows that these tubes are positioned into a recirculation zone, subject to a direct incidence of the flue gases. This fact leads to an excessive value for the maximum heat flux obtained with bare tubes on its upper surface, as shown in Figure 14. 
Optimization of extended surfaces on tubes of the radiant section of fired heaters
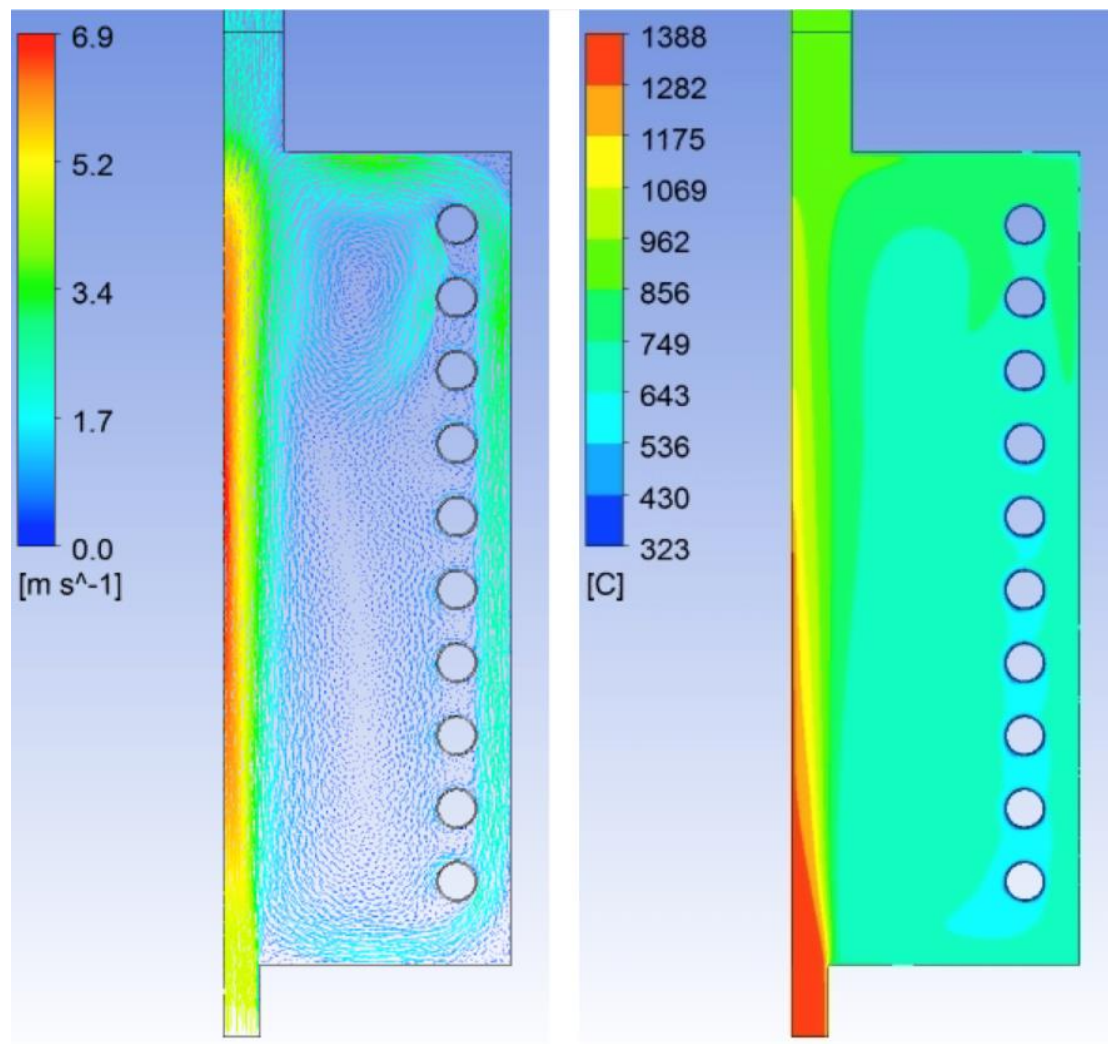

Figure 13. Flow representation and temperature profiles.

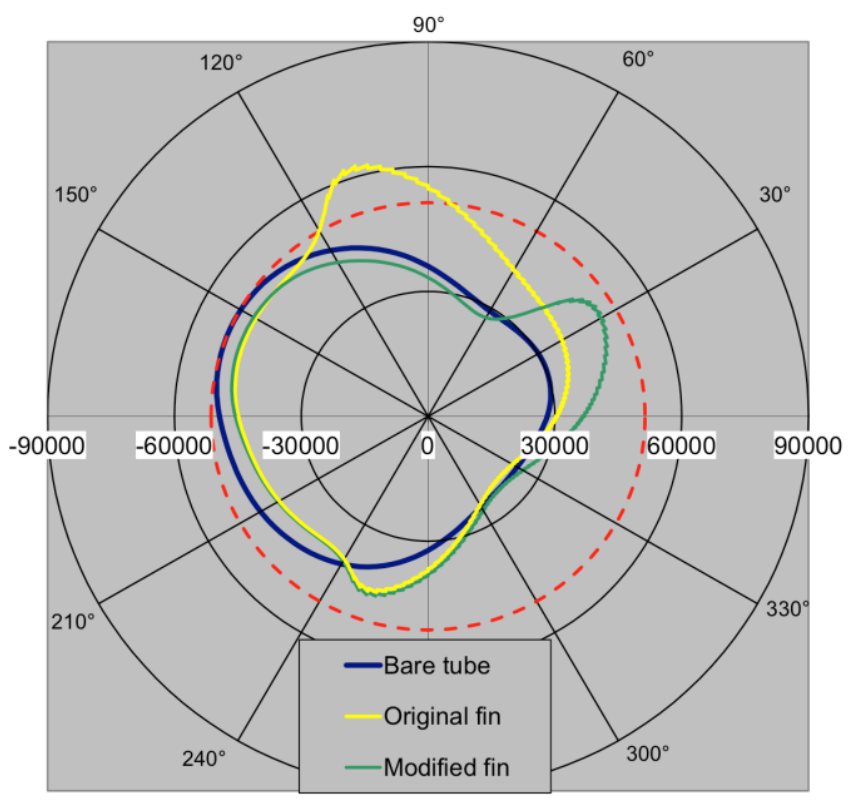

Tube 9 heat flux $\left[\mathrm{W} / \mathrm{m}^{2}\right]$

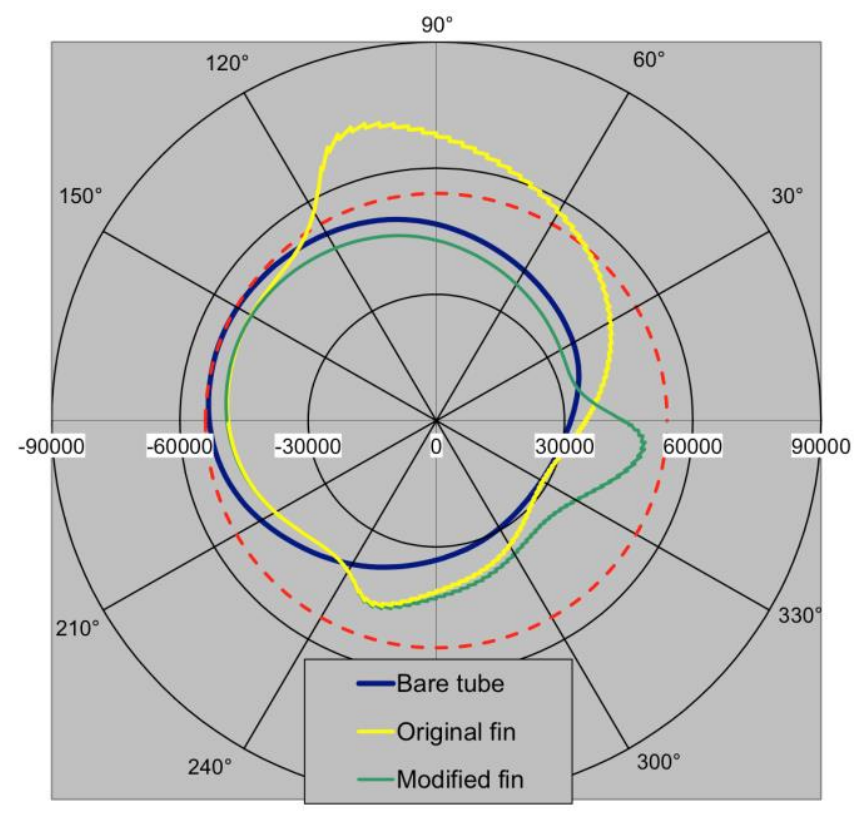

Tube 10 heat flux $\left[\mathrm{W} / \mathrm{m}^{2}\right]$

(a)

Figure 14. Heat flux distribution along the inner surface of tubes 9 and 10.

(b) 


\section{Optimization of extended surfaces on tubes of the radiant section of fired heaters}

In order to re-check the grid convergence, we re-ran these results, obtained with 376,086 cells, in a grid with 761,568 cells. The comparison between the two grids is presented in Table 1, where one can verify that relative deviations in the average and maximum heat flux, as well as in the $F_{\text {cir }}$ are less than $1 \%$.

Table 1. Grid convergence analysis of the results presented in Fig. 12.

\begin{tabular}{|c|c|c|c|c|c|c|c|c|c|}
\hline \multirow[b]{3}{*}{ Tube } & \multirow{2}{*}{\multicolumn{2}{|c|}{$\begin{array}{c}\bar{q} \\
\left(\mathrm{~W} / \mathrm{m}^{2}\right)\end{array}$}} & \multirow{3}{*}{ Deviation } & \multirow{2}{*}{\multicolumn{2}{|c|}{$\begin{array}{c}q_{\max } \\
\left(\mathrm{W} / \mathrm{m}^{2}\right) \\
\text { Mesh size }\end{array}$}} & \multirow{3}{*}{ Deviation } & & & \multirow{3}{*}{ Deviation } \\
\hline & & & & & & & \multicolumn{2}{|c|}{ Mesh size } & \\
\hline & $\begin{array}{c}376,086 \\
\text { cells }\end{array}$ & $\begin{array}{c}761,568 \\
\text { cells }\end{array}$ & & $\begin{array}{c}376,086 \\
\text { cells }\end{array}$ & $\begin{array}{c}761,568 \\
\text { cells }\end{array}$ & & $\begin{array}{c}376,086 \\
\text { cells }\end{array}$ & $\begin{array}{c}761,568 \\
\text { cells }\end{array}$ & \\
\hline 1 & 52632 & 52558 & $0.14 \%$ & 69562 & 69734 & $0.25 \%$ & 1.3217 & 1.3268 & $0.39 \%$ \\
\hline 2 & 48273 & 48374 & $0.21 \%$ & 73031 & 73408 & $0.51 \%$ & 1.5129 & 1.5175 & $0.31 \%$ \\
\hline 3 & 45997 & 45971 & $0.06 \%$ & 70649 & 70792 & $0.20 \%$ & 1.5360 & 1.5399 & $0.26 \%$ \\
\hline 4 & 43895 & 43899 & $0.01 \%$ & 66971 & 67406 & $0.65 \%$ & 1.5257 & 1.5355 & $0.64 \%$ \\
\hline 5 & 41078 & 41096 & $0.04 \%$ & 61839 & 62306 & $0.75 \%$ & 1.5054 & 1.5161 & $0.70 \%$ \\
\hline 6 & 38739 & 38729 & $0.03 \%$ & 55402 & 55444 & $0.08 \%$ & 1.4301 & 1.4316 & $0.10 \%$ \\
\hline 7 & 36967 & 37093 & $0.34 \%$ & 49281 & 49440 & $0.32 \%$ & 1.3331 & 1.3329 & $0.02 \%$ \\
\hline 8 & 35519 & 35554 & $0.10 \%$ & 43802 & 43810 & $0.02 \%$ & 1.2332 & 1.2322 & $0.08 \%$ \\
\hline 9 & 39571 & 39767 & $0.49 \%$ & 62664 & 63054 & $0.62 \%$ & 1.5836 & 1.5856 & $0.13 \%$ \\
\hline 10 & 46330 & 46198 & $0.29 \%$ & 72679 & 72694 & $0.02 \%$ & 1.5687 & 1.5735 & $0.31 \%$ \\
\hline
\end{tabular}

A new optimization process was carried out in order to adjust the parameter $\omega$ of the upper face of tubes 9 and 10. To this task, only the trapezoidal profile was considered, since the parabolic profile results were very similar. New simulations were performed and a cubic spline interpolation was used to fit the data. After identifying the region where the minimum objective function was located at, the geometries of the tubes 9 and 10 were optimized using the Particle Swarm method.

The results of this optimization procedure are shown in Figures 15 and 16. It is possible to observe a significant improvement in the uniformity of heat flux distribution to all tubes. The average reduction of the difference between the maximum and average heat flux was $28.1 \%$. The highest value obtained for the $F_{\text {cir }}$ factor was 1.53 , a significant reduction compared to the maximum value of 1.67 obtained with bare tubes. These results could be further improved with an individualized optimization of the other tubes, but the potential gain would be lower than those obtained for the tubes 9 and 10. 
Optimization of extended surfaces on tubes of the radiant section of fired heaters

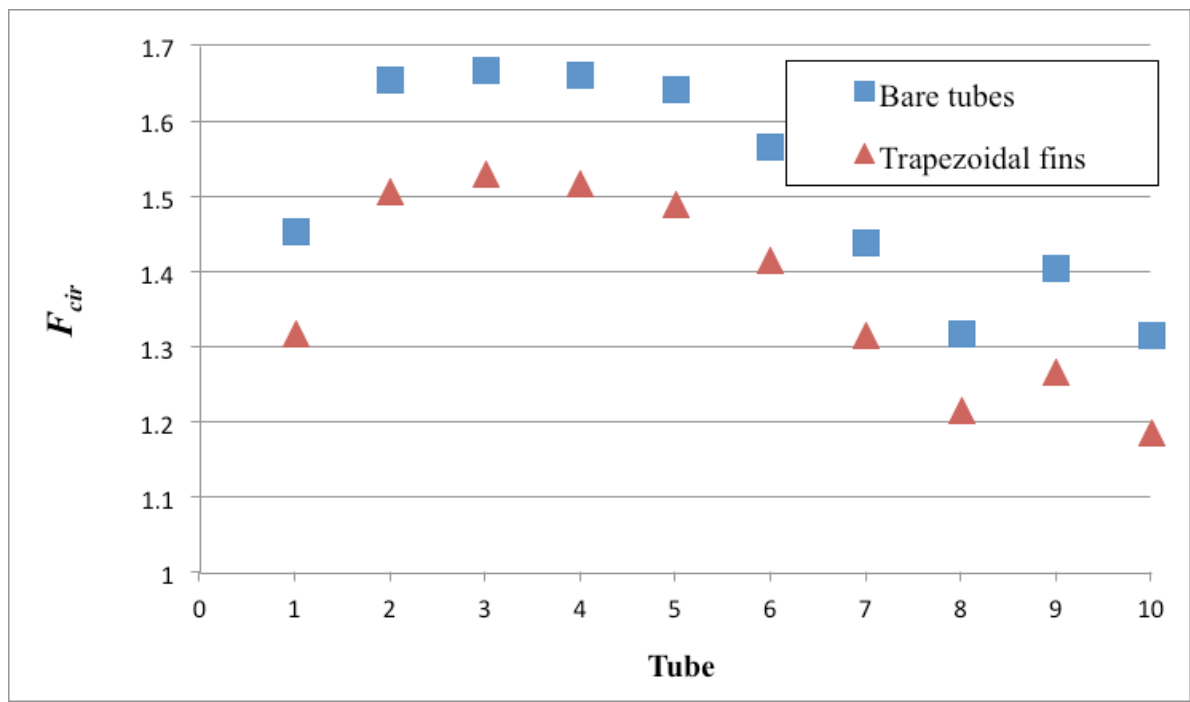

Figure 15. Circumferential heat flux distribution to the tubes.

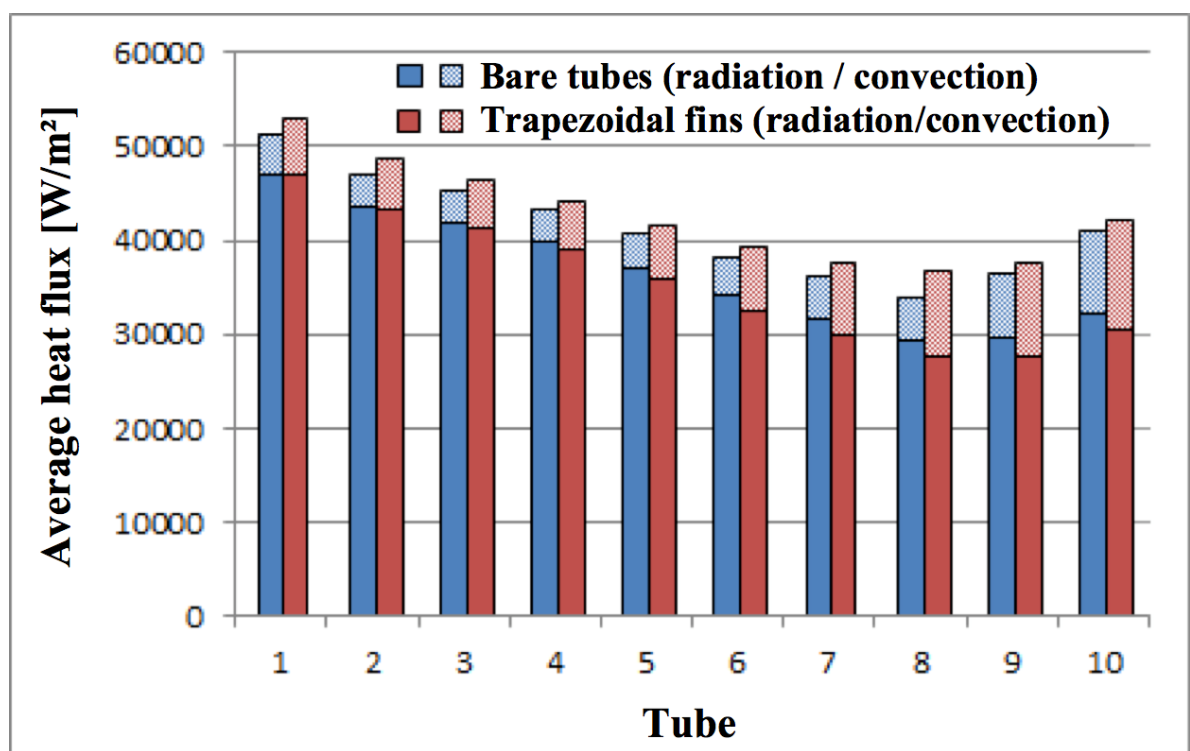

Figure 16. Average heat flux to the tubes.

Figure 16 shows that, in addition to allowing a better heat flux distribution in the tubes, the fins provided an increase in the overall heat transfer. Thus, the thermal efficiency of the combustion chamber was raised to $57.8 \%$, a gain of 1.6 point compared to the result obtained with the bare tubes, which leads to lower fuel consumption and emissions. The convective participation in heat transfer was increased, as shown in Figure 16 , resulting in a total contribution of $17.2 \%$, a significant increase compared to the $11.4 \%$ obtained without the fins. Nevertheless, the effects of radiation remain predominant.

\section{CONCLUSIONS}

This study investigated the potential of achieving a better heat flux distribution to the tubes of the radiation section of fired heaters by using extended surfaces. To this end, a simplified model and a refined finite volume model were used to represent the heat transfer mechanisms present in these equipment. With 
these results, a response surface technique and the Particle Swarm optimization method were used to determine the best geometric configurations for the proposed fin profiles.

The results obtained with the simplified model, which only considered radiative heat transfer, led to a reduction of the difference between the maximum and average heat flux on the internal tubes of the heater of $17 \%$ with the trapezoidal profile and $16 \%$ with the parabolic profile. When the effects of convection were included with the refined model, the gains were even greater, allowing an average reduction of the difference between the maximum and average heat flux per tube of about $28 \%$.

These results indicate that the use of extended surfaces in the tubes of the radiation section of fired heaters has the potential to significantly improve the heat flux distribution, reducing the risk factors that lead to the harmful processes of fluid degradation and coking. Thus, this application makes possible the design of combustion chambers with smaller dimensions and number of tubes, since it allows an increase in the average heat flux for a given maximum limit. It can also be an interesting alternative to services that require a more uniform heat flux distribution, especially compared to the complex double fired arrangement. In existing fired heaters, the replacement of bare tubes by finned tubes allows increased thermal efficiency and/or energy transfer capacity, without extrapolating the maximum heat flux recommended for the application.

Future studies may investigate new geometries for the extended surfaces, seeking for an even better heat flux distribution to the tubes. In addition, experimental evaluations may be performed in order to confirm the results predicted in this work.

\section{ACKNOWLEDGEMENTS}

This work was partly funded by the Brazilian agencies CNPq, CAPES, FAPERJ, and ANP/PRH. The support provided by PETROBRAS is also greatly appreciated.

\section{REFERENCES}

[1] BARLETTA, T., "Why Vacuum Unit Fired Heaters Coke", Petroleum Technology Quarterly, Q4, 2002.

[2] JEGLA, Z., KAHOUTEK, J., STEHLIK, P., "Design and Operating Aspects Influencing Fouling Radiant Coils of Fired Heaters Operated in Crude Oil Distilation Plants", In: Proceedings on International Conference on Heat Exchanger Fouling and Cleaning, pp. 7-14, 2011.

[3] PELINI, R. G., "Heat Flux And Film Temperature In Fired, Thermal-Fluid Heaters", Chemical Engineering, v. 115, n. 13, pp. 34-40, Dec. 2008.

[4] CATALA, K. A., KARRS, M. S., SIELI, G., "Advances in Delayed Coking Heat Transfer Equipment”, Hydrocarbon Processing, pp. 45-54, Feb. 2009.

[5] JIAO, J., MORAYKO, Y., THAILGAARD, M., et al., "Controlling Film Temperature in Fired Heaters", Petroleum Technology Quarterly, Q1, 2013.

[6] WEN, J. X., HUANG, M. Y., "CFD Modelling of Confined Jet Fires under Ventilation-Controlled Conditions", Fire Safety Journal, v. 34, n. 1, pp. 1-24, Feb. 2000.

[7] ORBEGOSO, E. M. M., Numerical Study of Thermal Radiation and its Interaction with the Soot Formed in Turbulent Combustion Fuels Liquid and Gaseous, PhD Thesis (in Portuguese), Pontifical Catholic University of Rio de Janeiro, Rio de Janeiro, RJ, Brazil, 2013. 
Optimization of extended surfaces on tubes of the radiant section of fired heaters

[8] COELHO, P. J., "Advances in the Discrete Ordinates and Finite Volume Methods for the Solution of Radiative Heat Transfer Problems in Participating Media”, Journal of Quantitative Spectroscopy \& Radiative Transfer, v. 145, pp. 121-146, 2014.

[9] STEFANIDIS, G. D., MERCI, B., HEYNDERICKX, et al., "CFD Simulations of Steam Cracking Furnaces using Detailed Combustion Mechanisms", Computers and Chemical Engineering, v. 30, n. 4, pp. 635-649, Feb. 2006.

[10] LAN, X., GAO, J., XU, C., et al., "Numerical Simulation of Transfer and Reaction Processes in Ethylene Furnaces", Chemical Engineering Research and Design, v. 85, n. 12, pp. 1565-1579, 2007.

[11] HÁJEK, J., JEGLA, Z., VONDÁL, J., "Numerical Analysis of Radiant Section of Fired Heater Focused on the Effect of Wall-Tube Distance", In: Proceedings of the 24th European Symposium on Computer Aided Process Engineering - ESCAPE 24, pp. 331-336, Budapest, Jun. 2014.

[12] API STD 530, Calculation of Heater Tube Thickness in Petroleum Refineries, $6^{\text {th }}$ ed., American Petroleum Institute, 2008.

[13] API STD 560, Fired Heaters for General Refinery Service, $4^{\text {th }}$ ed., American Petroleum Institute, 2007.

[14] LOBO, W. E., EVANS, J. E., "Heat Transfer in Radiant Section of Petroleum Heaters", Transactions of the American Institute of Chemical Engineers, v. 35, pp. 748-778, 1939.

[15] BERMAN, H. L., "How Combustion Conditions Influence Design and Operation", Chemical Engineering, v. 85, n. 18, pp. 129-140, Ago. 1978.

[16] BENKO, I., "Energy Conservation Through Increased Emissivity in Furnaces", Periodica Polytechnica Mechanical Engineering, v. 35, n. 4, pp. 235-245, 1991.

[17] LOWE, C., BRANCACCIO, N., BATTEN, D., et al., “Technology Assessment of Hydrogen Firing of Proccess Heaters”, Energy Procedia, v. 4, pp. 1058-1065, 2011.

[18] MORALES-FUENTES, A., PICÓN-NÚÑEZ, M., POLLEY, G. T., et al., "Analysis of the Influence of Operating Conditions on Fouling Rates in Fired Heaters", Applied Thermal Engineering, v. 62, n. 2, pp. 777-784, 2014.

[19] SHIH, T. H., LIOU, W. W., SHABBIR, A., et al., “A New k- $\varepsilon$ Eddy Viscosity Model for High Reynolds Number Turbulent Flows”, Computers \& Fluids, v. 24, n. 3, pp. 227-238, Mar. 1995.

[20] ANSYS, INC., ANSYS FLUENT Theory Guide, v. 14.0, Canonsburg, Nov. 2011.

[21] HOTTEL, H. C., SAROFIM, A. F., Radiative Transfer, $1^{\text {st }}$ ed., New York, McGraw Hill, 1967.

[22] CHANDRASEKHAR, S., Radiative Transfer, $1^{\text {st }}$ ed., New York, Dover Publication, 1960.

[23]COLAÇO, M. J., DULIKRAVICH, G. S., “A Survey of Basic Deterministic, Heuristic, and Hybrid Methods for Single-Objective Optimization and Response Surface Generation”, In: ORLANDE, H. R. B., MAILLET, O. F. D., COTTA, R. M. (eds), Thermal Measurements and Inverse Techniques, $1^{\text {st }}$ ed., cap. 10, EUA, CRC Press, 2011.

[24]KENNEDY, J. ELBERHART, R. C., "Particle Swarm Optimization", In: Proceedings of the 1995 IEEE International Conference on Neural Networks, v. 4, pp. 1942-1948, Perth, Australia, 1995. 